\title{
Semi-linear fractional systems with Caputo type multi-step differences
}

\section{EWA GIREJKO and DOROTA MOZYRSKA}

\author{
ABSTRACT. \\ A new class of fractional linear and semi-linear discrete-time systems described by the collection of state equa- \\ tions is introduced. The solution to the system is derived by the recursive formula. Presented results concern \\ the fractional $h$-difference operator.
}

Acknowledgement. The work was supported by Bialystok University of Technology grant G/WM/3/2012. The project was supported by the founds of National Science Centre granted on the bases of the decision number DEC-2011/03/B/ST7/03476.

\section{REFERENCES}

[1] Abdeljawad, T., On Riemann and Caputo fractional differences, Comput. Math. Appl., 62 (2011), No. 3, $1602-1611$

[2] Abdeljawad, T. and Baleanu, D., Fractional differences and integration by parts, J. Comput. Anal. Appl., 13 (2011), No. 3, 574-582

[3] Agrawal, O. P., Generalized variational problems and Euler-Lagrange equations, Comput. Math. Appl. 59 (2010), No. 5, 1852-1864

[4] Atici, F. M. and Eloe, P. W., A transform method in discrete fractional calculus, Int. J. Difference Equ., 2 (2007), No. $2,165-176$

[5] Atici, F. M. and Eloe, P. W., Initial value problems in discrete fractional calculus, Proc. Amer. Math. Soc., 137 (2008), No. 3, 981-989

[6] Baleanu, D., Machado, J. A. T. and Luo, A. C. J., Fractional dynamics and control, New York: Springer Science and Business Media, 2012

[7] Bastos, N. R. O., Ferreira, R. A. C. and Torres, D. F. M., Necessary optimality conditions for fractional difference problems of the calculus of variations, Discrete Contin. Dyn. Syst., 29 (2011), No. 2, 417-437

[8] Caponetto, R., Fractional order systems : modeling and control applications, World scientific series on nonlinear science. Series A, Monographs and treatises, Singapore : World Scientific, 2010

[9] Chen, F., Luo, X. and Zhou, Y., Existence results for nonlinear fractional difference equation, Adv. Difference Equ., (2011), doi:10.1155/2011/713201, Article ID 713201

[10] Diethelm, K., The analysis of fractional differential equations. An application-oriented exposition using differential operators of Caputo type, Springer-Verlag, Berlin, 2010

[11] Ferreira, R. A. C. and Torres, D. F. M., Fractional h-difference equations arising from the calculus of variations, Appl. Anal. Discrete Math., 5 (2011), No. 1, 110-121

[12] Goodrich, C. S., Existence and uniqueness of solutions to a fractional difference equation with nonlocal conditions, Comput. Math. Appl., 61 (2011), No. 2, 191-202

[13] Hermann, R., Fractional calculus: an introduction for physicists, New Jersey: World Scientific, 2011

[14] Holm, M. T., The theory of discrete fractional calculus: Development and application, University of Nebraska Lincoln, 2011

[15] Kaczorek, T., Reachability and controllability to zero of positive fractional discrete-time systems, Machine Intelligence and Robotic Control, 6 (2007), No. 4

Received: 05.03.2013; In revised form: 16.10.2013; Accepted: 15.01.2014

2010 Mathematics Subject Classification. 26A33, 39A10.

Key words and phrases. Fractional difference operator, discrete-time systems, difference equations, fractional derivative.

Corresponding author: Ewa Girejko; e.girejko@pb.edu.pl 
[16] Miller, K. S. and Ross, B., Fractional difference calculus, Proceedings of the International Symposium on Univalent Functions, Fractional Calculus and their Applications, Nihon University, Kōriyama, Japan, 1988, 139-152

[17] Mozyrska, D. and Girejko, E., Overview of the fractional difference operators appearing in linear systems theory, Advances in Harmonic Analysis and Operator Theory - The Stefan Samko Anniversary Volume, Operator Theory: Advances and Applications, Birkhäuser Basel, 229 (2013), 253-267

[18] Ortigueira, M. D., Fractional discrete-time linear systems, Munich, Germany, New York 1997, 2241-2244

[19] Ortigueira, M. D., Fractional calculus for scientists and engineers, Dordrecht : Springer, 2011

[20] Podlubny, I., Fractional Differential Equations, Mathematics in Sciences and Engineering, 198, Academic Press, San Diego, 1999

[21] Tarasov, V. E., Fractional dynamics : applications of fractional calculus to dynamics of particles, fields and media, Nonlinear physical science, Heidelberg : Springer, 2010

[22] Torres, D. F. M. and Malinowska, A. B., Introduction to the Fractional Calculus of Variations, Imperial College Press, 2012

BIALYSTOK UNIVERSITY OF TECHNOLOGY,

FACULTY OF COMUTER SCIENCE

WIEJSKA 45A, 15-351, BIAŁYSTOK, POLAND

E-mail address: e.gire jko@pb.edu.pl

BIALYSTOK UNIVERSITY OF TECHNOLOGY, FACULTY OF COMUTER SCIENCE

WiejSKA 45A, 15-351, BiAŁYSTOK, POLAND

E-mail address: d.mozyrska@pb.edu.pl 